\title{
Margaret McCartney: Who's measuring the harm caused by the new benefits system?
}

\author{
Margaret McCartney general practitioner, Glasgow
}

The Disability Living Allowance benefit started to become Personal Independence Payments (PIPs) in 2013. These payments, which are not means tested, go to people with long term disabilities who need help to cook, eat, travel, wash, or dress, for example.

The UK government's stated aim was to reassess each person receiving Disability Living Allowance to reduce "caseload and expenditure" by $20 \% .^{1}$ After a "spending to save" philosophy the government gave two private companies, Atos and Capita, contracts worth about $£ 500 \mathrm{~m}^{2}$ and $£ 140 \mathrm{~m}^{3}$ to administer the assessments and, supposedly, to save us $£ 3 \mathrm{bn}$. The rationale was a need for objective functional assessments and continual reassessment.

Many in the media have focused on "benefit cheats." Anxiety is a common, unintended outcome of health and social care policies that is rarely taken seriously enough, let alone measured. The benefits system should be fair, of course, but criminals are rare. The uncertainty of the new PIP thresholds has created much fear, and my repeated observation is that guilt, embarrassment, and a sense of being made to "beg" all surround the copious form filling required when applying.

Backlogs in carrying out assessments have led to months of worried sleeplessness that have gone largely uncounted. The Public Accounts Committee described the system as "nothing short of a fiasco," one creating stress and distress ${ }^{4}$ - but evidence of harms is not being systematically collected.

It is ethical to want to ensure that people with chronic conditions can participate in society. But it is self interest, too: firstly, because we, or people we care about, may become disabled; and, secondly, because a fairer society is better for us all. ${ }^{5}$

The first independent review of PIPs focused on problems with administration of the assessments ${ }^{6}$ rather than their effect on people, families, or the NHS, which is called on to help with delays and uncertainties in the system.

We should answer the basic questions first, because social care is fundamentally healthcare. Where was the evidence that we could safely and humanely reduce our social welfare spending without causing harm? How do we know that this new system works well enough?
Recent data show that $£ 1.2 \mathrm{bn}$ - that is, $0.7 \%$ of the total-is lost to benefit fraud. However, $£ 1.5 \mathrm{bn}$ of benefits are underpaid, meaning a net shortfall in claims. ${ }^{7}$ Changing the means by which benefits are made should surely work on a safety first principle. The confusing and slow claims system seems designed to exclude people, and it is often left to charities to help people access the funds that they are allowed. Is this the kind of care that chronically ill and disabled people deserve?

Competing interests: I have read and understood the BMJ policy on declaration of interests and declare the following interests: I'm an NHS GP partner, with income partly dependent on Quality and Outcomes Framework points. I'm a part time undergraduate tutor at the University of Glasgow. I've written two books and earn from broadcast and written freelance journalism. I'm an unpaid patron of Healthwatch. I make a monthly donation to Keep Our NHS Public. I'm a member of Medact. I'm occasionally paid for time, travel, and accommodation to give talks or have locum fees paid to allow me to give talks but never for any drug or public relations company. I was elected to the national council of the Royal College of General Practitioners in 2013 and am chair of its standing group on overdiagnosis. I have invested a small amount of money in a social enterprise, Who Made Your Pants?

Provenance and peer review: Commissioned; not externally peer reviewed.

The BMS s readers can buy Margaret's new book, Living with Dying, for $£ 7.99$ (RRP £11.99) including UK delivery from www.pinterandmartin. com with checkout code BMJ799.

1 Work and Pensions Committee. Monitoring the performance of the Department for Work and Pensions in 2012-13. 2014. www.publications.parliament.uk/pa/cm201314/cmselect/ cmworpen/1153/115306.htm.

2 Plimmer G. UK tests for disabled claimants in chaos as Atos quits contract. Financial Times 27 March 2014. http://on.ft.com/1yFAtQI.

Capita. Capita signs PIP contract. 2 Aug 2012. http://bit.ly/1Bz3lp3.

4 Public Accounts Committee. Implementation of Personal Independence Payments nothing short of fiasco. 20 June 2014. http://bit.ly/1uklp3W.

5 European Portal for Action on Health Inequalities. Marmot reviews. www.health-inequalities. eu/HEALTHEQUITY/EN/about_hi/marmot_reviews/.

6 Gray P. An independent review of the Personal Independence Payment assessment. Stationery Office 2013. http://bit.ly/1KXYTZa.

7 Department for Work and Pensions. Fraud and error in the benefit system 2013-14 estimates. 6 Nov 2014. http://bit.ly/1yDUgwZ. 
